\title{
Effect of Foliage Length on Signal Attenuation in Millimeter Band at $35 \mathrm{GHz}$ Frequency
}

\author{
D.R.Godara \\ Research Scholar \\ Bhagwant University \\ Ajmer Rajasthan, \\ India
}

\author{
J.S.Purohit, Ph.D \\ Asst.director \\ Technical Education, \\ Rajasthan
}

\author{
Sandeep \\ Rankawat \\ Research Scholar \\ Bhagwant University \\ Ajmer, \\ Rajasthan, India
}

\author{
S.K.Modi \\ Assistant prof. \\ Govt. Engineering \\ CollegeBikaner
}

\begin{abstract}
The appearance of the foliage medium in the path of the communication link in Millimeter band has found to play a significant role on the quality of services for wireless communication. In this paper an attempt has been made to quantify the signal attenuation of microwave signal at $35 \mathrm{GHz}$ due to varying foliage length so the communication with any degree of confidence can be assured in a foliage environment. It concludes that the signal attenuation doesn't increase linearly as the number of trees or the length of foliage increases. For the measurement of signal attenuation, a Gunn oscillator trans-receiver system of $35 \mathrm{GHz}(100 \mathrm{~mW})$ is used.
\end{abstract}

\section{Keywords}

Millimeter wave, broadband, antenna, modulation, demodulation, power amplification, signal attenuation.

\section{INTRODUCTION}

The millimeter wave spectrum $(30-300 \mathrm{GHz})$ is of increasing interest to service providers and systems designers because of the wide bandwidths available for carrying communications at this frequency range. Such wide bandwidths are valuable in supporting applications such as high speed data transmission and video distribution.

To fulfill the increasing demand of high rate data and wideband communication, Ka band $(26-40 \mathrm{GHz})$ is under consideration. For the establishment of more and more communication system in the millimeter wave band it becomes necessary to study the propagation attenuation due to various parameters of foliage. The Planning of millimeter wave spectrum use must take into account the propagation characteristics of radio signals at this

frequency range [1]. The signals at lower frequency bands can propagate for many miles and penetrate more easily through vegetation and foliage, millimeter wave signals can travel only a few miles or less and do not penetrate solid material very well[4]. The difference in foliage penetration for $10 \mathrm{GHz}$ and $35 \mathrm{GHz}$ is not dramatic, while for $90 \mathrm{GHz}$ it is considerably higher. This leads to the result that the $35 \mathrm{GHz}$ band is well suited for fire detection behind foliage [9]. Millimeter waves can permit more densely packed communications links, thus providing very efficient spectrum utilization, and they can increase security of communication transmissions. Attenuation due to foliage and vegetation has long been recognized as a major limitation to reliable communication system operating at frequency above $10 \mathrm{GHz}$ [2]. It restricts the path length of radio communication systems and limits the use of higher frequencies for line-ofsight microwave links. The objective of this research work is

to collect sufficient data on signal attenuation at $35 \mathrm{GHz}$ frequency due to signal propagation through foliage prevailing in the desert area of north-west part of India. These data can be used to generate algorithm to control the microwave link transmission power so that in favourable conditions it transmits minimum power and during adverse conditions like foliage with fog, it may transmit sufficient power to ensure reliable communication.

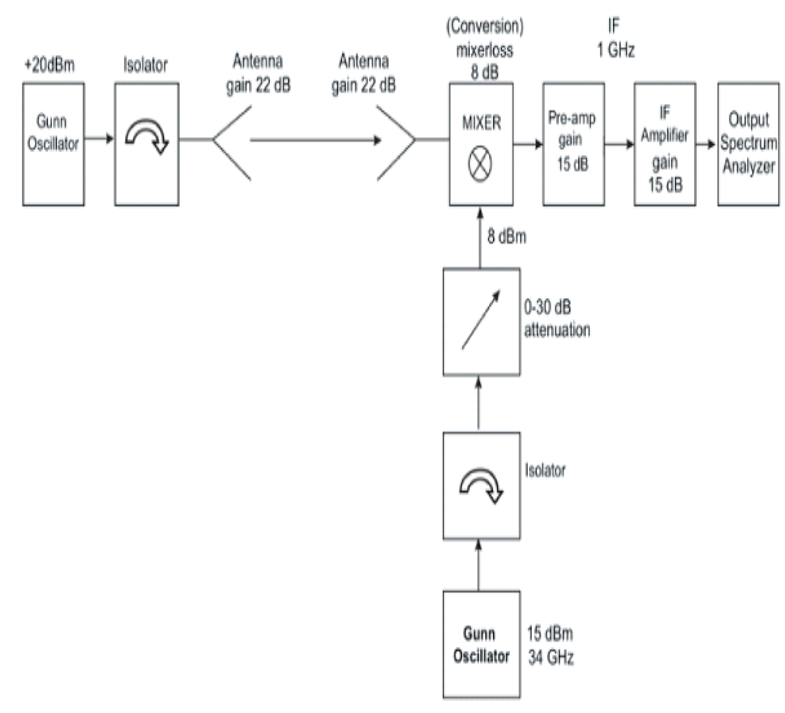

Fig1. Block Diagram of $35 \mathrm{GHz}$ Link System

\section{EXPERIMENT SETUP}

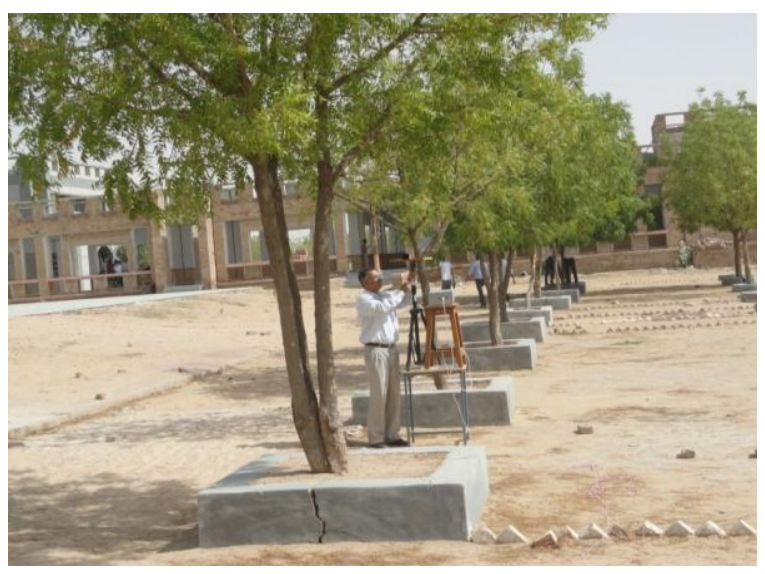

Fig 2.Experimental site at Govt. Engineering College Bikaner

The block diagram of the transmitter and receiver sections of the $35 \mathrm{GHz}$ system are shown in figure 1 . The millimeter 
wave link system comprises a continuous wave $35 \mathrm{GHz}$ transmitter using a $100 \mathrm{~mW}(20 \mathrm{dBm})$ Gunn source with a transmitting antenna of 18 degree beam width and $22 \mathrm{~dB}$ gain.

The receiver section has the requisite down conversion and de-spreading circuitry. The signal received by the horn antenna is down converted to the intermediate frequency (IF) followed by a cavity mixer with a local oscillator operating at $34 \mathrm{GHz}$. The IF of $1.0 \mathrm{GHz}$ output of the mixer is fed to a preamplifier followed by a driver amplifier. The amplified IF signal is displayed on a spectrum analyzer. The spectrum analyzer shows both received power in $\mathrm{dBm}$ and central peak's frequency. The spectrum analyzer also allows the received power and spectrum to be saved into a laptop or computer. Receiver is capable of providing a useable base band output with received millimeter wave signal levels as low as $-80 \mathrm{dBm}$

During this experiment, the signal attenuation measured with respect to the number of Neem trees of almost same size. The five trees were considered one by one in the path between transmitter and receiver. The observations show that $26.3 \mathrm{~dB}$ attenuation was found when five trees of equal depth (5 feet) and height (7 feet) each were in the path. The attenuation versus number of Neem trees measurement result shows that initially high attenuation and then becoming more gradual after three trees. It means that the signal is attenuated as it travels through these trees, but also as the signal passes through several trees it becomes randomly polarized explaining the gradual transition in attenuation. There is a gradual increase in attenuation with the increasing in number of trees.

Result and observations

Canopy Size $($ Neem $)=$ Height 7 feet

and canopy size 5 feet.

Gunn Voltage $=3.87$ Volt

and Current $=0.53$ Ampere

IF frequency $=1.08 \mathrm{GHz}$,

Reference Level $=-12 \mathrm{dBm}$

Height of Transmitting and Receiving Antenna $=7 \mathrm{ft}$.

Table: 1 Attenuation with different number of trees

\begin{tabular}{|l|l|l|l|l|}
\hline $\begin{array}{l}\text { No. of } \\
\text { Trees }\end{array}$ & $\begin{array}{l}\text { Distan } \\
\text { ce in } \\
\text { feet }\end{array}$ & $\begin{array}{l}\text { Receive } \\
\text { d } \\
\text { Power } \\
\text { LOS } \\
(\mathrm{dBm})\end{array}$ & $\begin{array}{l}\text { Received } \\
\text { Power LOS } \\
\text { with foliage } \\
(\mathrm{dBm})\end{array}$ & $\begin{array}{l}\text { Attenuation } \\
(\mathrm{dB})\end{array}$ \\
\hline 1 & 39 & -37.3 & -43.7 & 6.4 \\
\hline 2 & 57 & -39.9 & -52.1 & 12.2 \\
\hline 3 & 75 & -41.3 & -60.1 & 18.8 \\
\hline 4 & 93 & -43.3 & -66.5 & 23.2 \\
\hline 5 & 111 & -46.3 & -72.6 & 26.3 \\
\hline
\end{tabular}

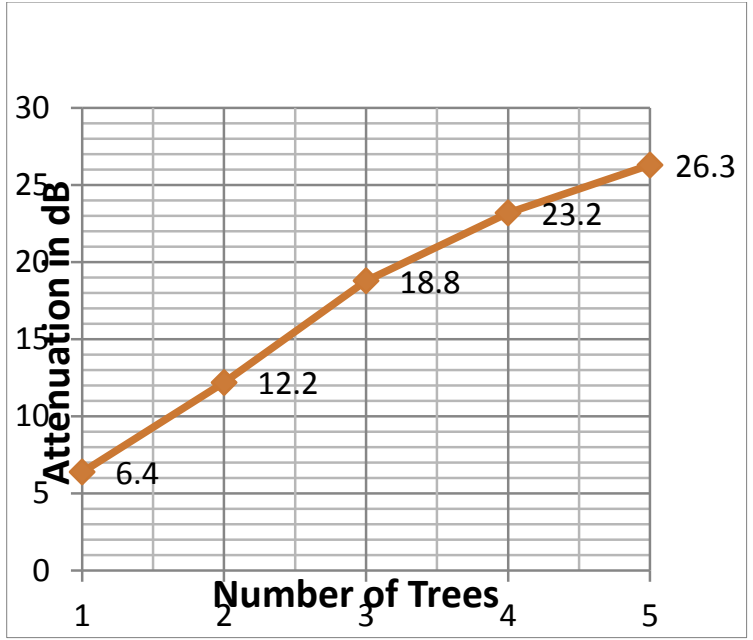

Fig 3. Signal attenuation with number of trees

\section{CONCLUSIONS}

The observations taken during present work concludes that the signal attenuation at $35 \mathrm{GHz}$ is not increasing proportional to the number of trees or the foliage depth. The effect of foliage length in the path of a point to point link influence the received signal as by providing an additional attenuation to that of free space but due to scattering and depolarization of signal by longer foliage length results in lateral contribution to the received signal. The experimental result shows that for foliage length $5 \mathrm{feet}$, the signal attenuation is $1.28 \mathrm{~dB} / \mathrm{ft}$ and for foliage length 25 feet, the signal attenuation is $1.052 \mathrm{~dB} / \mathrm{ft}$.

\section{REFERENCES}

[1] Calla, O.P.N., Purohit, J.S. and Sangwa, R.N. (2005). Effect of natural phenomenon like sand/dust storm, rain and desert foliage on propagation of millimeter waves in Thar desert. Presented at International Conference on Physics for world and Society Celebration of world year of physics 2005 under joint Auspices of University of Rajasthan, Jaipur and Engineering College, Bikaner, Dec. 2-4, p. 104.

[2] Weissberger, M. A., An initial critical summary of models for predicting the attenuation of radio waves by foliage," ECAC-TR-81-101, Electromagn. Compat. Analysis Center, Annapolis, MD, 1981.

[3] Seville, A. and K. H. Craig,Semi-empirical model for millimeter-wave vegetation attenuation rates," Electron Lett., Vol. 31,No. 17, 1507-1508, 1995.

[4] Seville, A., Vegetation attenuation: Modeling and measurements at millimeter frequencies," Proc. 10th IEE Int. Conf. Antennas Propagation., 2.5-2.8, Edinburgh, Scotland, Apr. 1997.

[5] Savage N., D. Ndzi, A. Seville, E. Vilar, and J. Austin, IRadio wave propagation through vegetation: Factors influencing signal attenuation," Radio Sci., Vol. 38, No. 5, 1088, 2003.

[6] Al-Nuaimi, M. O. and A. M. Hammoudeh, Measurements and predictions of attenuation and scatter of microwave signals by trees," IEE Proc. Microw. Antennas Propag., Vol. 141, No. 2, 70- 76, 1994.

[7] Didascalou, D., M. Younis, and W. Wiesbeck, Millimeter-wave scattering and penetration in isolated 
vegetation structures," IEEE Trans. Geosci. Remote Sensing, Vol. 38, No. 5, 2106\{2113, 2.

[8] IWBB,International forest fire protection project, Federal state of north Rhine Westphalia,2008 and Foliage penetration upto millimeter wave frequency N.EssenD.Nubler,N.Vonwahl S. Heinen and S.Sieger,Franhofer Inst. Of higher frequency physics and Radar Technology Germany.

[9] Dr M M Sharma, D R Godara, Sandeep Rankawat; "Propagation study of Millimeter Wave Based on rain Attenuation at $35 \mathrm{GHz}$, Measured in Western Rajasthan"; International Conference on Microwave, Antenna propagation and Remote Sensing, ICMARS2009; International Centre for Radio Science (ICRS), Jodhpur; 19-21 December, 2009.

[10] D.R.Godara, S.K.Modi, Rupesh Kumar Rawat "Experimental studies on millimeter wave scattering from ground and vegetation at $35 \mathrm{GHz}$ " International Journal of Soft Computing and Engineering (IJSCE) ISSN: 2231-2307, Volume-1, Issue-6, January 2012

\section{AUTHOR'S PROFILE}

D.R.Godara He completed his B.E. and M.E in Electronic and Communication Engineering from MBM Engg. college, Jodhpur, India. His area of interests includes Antenna, Microwave \& wireless communication. He published around 10 papers in National /International conferences. He is presently working as Associate Professor in Electronic and Communication Department in Engineering college Bikaner. He has 22 years experience in Teaching and Research and 2 years experience in industry.
Dr.J.S.Purohit He completed his M.E in Electronics \& communication Engineering and Ph.D. in Microwave Engineering His area of interest is Microwave Propagation. He published around 14 Research papers. He is presently Asst. director at Technical Education Rajasthan. He has 25 years experience in Teaching and Research..

Sandeep rankawat $\mathrm{He}$ completed his B.E. Degree in Electronics and Communication Engineering from Rajasthan University, Jaipur in year 2004 and M.Tech from MNIT, Jaipur, in 2010. His area of interests includes Antenna, Microprocessor. He is working as Assistant Professor in Electronic and Communication Department at Engineering college Bikaner. He has 9 years Teaching experience. He published many papers in National /International conferences.

Sharwan Kumar Modi He completed his B.E. Degree in Electronics and Communication Engineering from Rajasthan University, Jaipur in year 2008 and M.Tech in Electronic and Communication from JNU, Jaipur, India in 2011.

He was completed diploma in Electronics Engg. from BTER Jodhpur in year 2004.His area of interests includes Electronics Devices \& Circuits, Digital Communication, Analog communication. He is presently working as Assistant Professor in Electronic and Communication Department in Engineering college Bikaner. He has 5 years Teaching experience. He published around many papers in National /International conferences. 